\title{
O judô adaptado como ferramenta para a reabilitação do equilíbrio de crianças com deficiência visual
}

https://doi.org/10.11606/issn.1981-4690.v35i2p187-194
Ana Carolina Pereira Nunes Pinto* J osiane de Oliveira Lima** Fernanda Gabriella de Siqueira Barros Nogueira* Said Kalume Kalif*
*Universidade Federal do Amapá, Macapá, AP, Brasil.

**Universidade da Amazônia, Belém, PA, Brasil.

\section{Resumo}

Crianças com deficiência visual podem apresentar atrasos no desenvolvimento do equilíbrio. 0 Judô é um esporte adaptado aos deficientes visuais, porém, pouco se sabe sobre seus efeitos em crianças com deficiência visual. 0 objetivo deste estudo foi verificar se o judô pode melhorar o equilibrio de crianças com deficiência visual. Neste estudo, nove crianças com deficiência visual, com idade entre 6 e 12 anos, que nunca haviam praticado judô, participaram de um protocolo de treinamento deste esporte durante 8 semanas. Para avaliação do equilibrio, aplicamos a Escala de Equilíbrio de Berg (EEB), o Teste de Alcance Funcional (TAF) e a Estabilometria, analisando as oscilações dos pés esquerdo e direito e do corpo. Para rejeição da hipótese nula foi previamente fixado o nível alfa $=0.05$. Registramos diferença estatisticamente significativa para a EEB ( $p$-valor $\left.=0,0069^{*}\right)$ entre as avaliações antes $(42,2+8,7)$ e após $(54,1+2,4)$ o treinamento. Também encontramos diferença entre os valores anteriores $(11,6 \pm 6,5 \mathrm{~cm})$ e posteriores $(25,6 \pm 7,6 \mathrm{~cm})$ ao treinamento para o TAF ( $p$-valor $<0,001)$, para as oscilações do pé esquerdo $(0,9 \pm 0.6 \mathrm{~cm}-0,4 \pm 0,2 \mathrm{~cm})$ ( $p$-valor 0,031$)$, pé direito $(1,5+1,5-0,8+0,6)$. ( $p$-valor 0,038$)$ e do corpo $(2,8 \pm 1,1 \mathrm{~cm}-1,6 \pm 0,7 \mathrm{~cm})$. (p-valor 0,015$)$. A prática do judô pode ser uma ferramenta importante na estratégia de reabilitação do equilíbrio de crianças com deficiência visual.

Palavras-chave: Pessoas com deficiência visual; Equilíbrio postural; Artes marciais; Esportes.

\section{Introdução}

Dentre as diversas formas de deficiências existentes, as visuais são as mais prevalentes. Dados da Organização Mundial da Saúde indicam que cerca de 285 milhões de pessoas têm deficiência visual no mundo todo, das quais 39 milhôes são cegas ${ }^{1}$.

A cegueira pode ser congênita ou adquirida. Cego congênito é o indivíduo que nasceu sem a visão ou que a perdeu antes dos cinco anos de idade. Este indivíduo não possui informações visuais úteis para a realização de suas tarefas. A cegueira adquirida, por sua vez, acomete pessoas após os cinco anos de idade. Assim, essas possuem referências visuais anteriores à deficiência e mesmo que com o passar do tempo percam a recordação dessas imagens mentais, continuam a realizar suas tarefas cotidianas com padróes de pessoas com visão normal ${ }^{2}$.

Em relação ao desenvolvimento da criança, caso náo seja adequadamente estimulada, a escassez de informaçôes visuais pode ocasionar prejuízos em diversos aspectos, tais como atrasos no campo motor, cognitivo, emocional e social ${ }^{3}$.

A criança com visão normal, em geral, tem melhor desempenho em provas de equilíbrio do que a criança com deficiência visual ${ }^{4,5}$. A manutenção do equilíbrio depende da integridade anatômica e funcional dos sistemas que controlam a função motora, sensorial e nervosa ${ }^{6}$. Distúrbios do equilíbrio podem levar à predisposiçâo a quedas 
e lesôes, medo de cair novamente, redução da mobilidade e da autonomia social ${ }^{7}$.

O judô é um desporto que possibilita que os deficientes visuais pratiquem-no sem necessidade de grandes adaptaçôes, sendo, inclusive, um esporte paralímpico ${ }^{8}$. Sabe-se que estímulos considerados importantes ao desenvolvimento motor da criança, tais como estímulos labirínticos, desequilíbrios, balanços, rotações,

\section{Método}

O presente estudo foi aprovado pelo Comitê de Ética e Pesquisa local, com o número de aprovação 325249/2010, em acordo com a Resolução 196/96 do Conselho Nacional de Saúde. O tamanho amostral foi calculado para a escala de equilíbrio de Berg, uma variável com padróes já estabelecidos na literatura. Para tanto, consideramos as seguintes estimativas obtidas com base bibliográficas: Desvio Padrão $=3$; Diferença a ser detectada: 3,0; Nível de significância: 5\%; Poder do teste: $80 \%$; Teste de hipótese: uni-caudal; Tamanho da amostra calculado: 22. Realizamos o cálculo do tamanho da amostra por meio de análise on-line disponível no site http://lee.dante.br/pesquisa/amostragem/ calculo_amostra.html.

Realizamos uma triagem entre os alunos do Instituto José Álvares de Azevedo, o maior centro de atenção especializada aos deficientes visuais de Belém-PA, com o intuito de recrutar crianças que se enquadrassem nos critérios de inclusão. Segundo a coordenadoria do instituto, o total de 26 crianças com deficiência visual na faixa etária de 6 a 12 anos frequentavam a instituição. Dentre estas, incluímos na pesquisa, apenas as que possuíam atestado médico de aptidão clínica para a prática de judô e cujos pais ou responsáveis legais consentiram com a participação no estudo. Excluímos do estudo crianças que haviam tido experiência prévia com a prática do judô e que possuíam outras deficiências e/ou doenças que pudessem interferir no controle do equilíbrio.

Após triagem dos alunos, obtivemos um total de 10 crianças e, então, iniciou-se a coleta de dados. Uma criança foi excluída após o início da coleta por não haver realizado os testes finais. Realizamos avaliaçôes do equilíbrio antes e após a realização do protocolo de treinamento, utilizando a Escala de Equilíbrio de Berg, o Teste de Alcance Funcional Anterior; e a avaliação das oscilações dos pés e do estímulos de contato, são comumente utilizados na prática do judô. Por outro lado, pouco se sabe a respeito do efeito do treinamento do judô no desenvolvimento motor de crianças com deficiência visual. Desta forma, este estudo teve o objetivo de analisar o efeito de um protocolo de treinamento baseado em movimentos do desporto judô sobre o equilíbrio de crianças com deficiência visual com idade entre 6 e 12 anos.

corpo através da estabilometria.

Para a realização das tarefas da Escala de Equilíbrio de Berg, foi realizado previamente o reconhecimento tátil do local e do material utilizado nas tarefas, bem como a descrição verbal minuciosa a respeito das tarefas a serem realizadas, até que a criança compreendesse. A seguir, as crianças realizaram as tarefas propostas, sendo supervisionadas pelo examinador. A escolha sobre qual membro inferior ficaria em pé durante o teste ficaram a critério da criança.

Para a realização do Teste de Alcance Funcional, a criança era posicionada perpendicularmente à parede, a $10 \mathrm{~cm}$ de distância da mesma, em posiçấo ortostática, com os pés paralelos e levemente separados. $\mathrm{O}$ membro superior mais próximo da parede foi posicionado com o ombro flexionado a $90^{\circ}$, cotovelo estendido, punho em posição neutra e dedos flexionados. A seguir, a criança era instruída a inclinar-se anteriormente, o máximo possível, e manter a posição por três segundos, sem retirar os calcanhares do chão, encostar ou apoiar-se na parede ou dar um passo. Uma fita métrica foi fixada à parede, paralela ao chão, na altura do acrômio de cada criança e o comprimento do braço da criança foi descontado. O alcance máximo foi medido através da localização final da ponta do terceiro metacarpo em centímetros. Cada criança realizou três tentativas. A média dos três registros foi levada em consideraçấo.

Para a avaliação por meio da estabilometria, utilizamos um Baropodômetro eletrônico, composto por uma plataforma acoplada a um sistema computadorizado e a sensores eletrônicos capazes de reconhecer as informaçôes de apoio plantar. Realizamos a análise da oscilaçáo do centro de pressão através da avaliação estabilométrica bipodálica estática. O examinador pediu que a criança se posicionasse em apoio bipodálico sobre a plataforma, com braços no prolongamento do corpo e cabeça posicionada de forma a deixar os olhos 
voltados para frente e a instruiu a permanecer imóvel por 20 segundos para análise do equilíbrio estático. Os valores das oscilaçóes do pé direito, pé esquerdo e do corpo foram analisados.

O examinador dos três testes diferiu dos monitores e professores que supervisionaram os treinamentos e, nenhum destes, possuía relação direta com os autores do estudo. Após as avaliaçóes, foi colocado em prática o protocolo de treinamento do desporto judô.

\section{Protocolo de treinamento do desporto J udô}

Não há na literatura nenhum protocolo de treinamento de judô específico para praticantes iniciantes com deficiência visual. Neste contexto, elaboramos um protocolo, buscando adequar-se às necessidades desses indivíduos. $\mathrm{O}$ protocolo baseouse em uma aula básica de judô para principiantes e fundamentou-se nos princípios metodológicos do ensino do judô para crianças, encontrados na literatura.

Antes do início do protocolo de treinamento, houve uma aula de "ambientação", em que as crianças realizaram o reconhecimento tátil do ambiente, vestimenta, dentre outros, e foram esclarecidas quaisquer dúvidas acerca dos implementos e materiais utilizados. Os treinamentos foram realizados em dias intercalados, totalizando 30 aulas.

Os treinamentos tiveram duração entre $64 \mathrm{e}$ 83 minutos e foram divididos em 4 momentos: aquecimento geral, aquecimento específico, parte principal e volta à calma.

O aquecimento geral teve duração aproximada de 5 minutos, sendo constituído de corrida lenta, saltos no mesmo lugar e nas direçóes antero-posterior e médio-lateral e polichinelo.

$\mathrm{O}$ aquecimento específico durou entre $20 \mathrm{e}$ 30 min e foi composto de atividades de puxar e empurrar, segurando o parceiro pela vestimenta; e ensinamento da forma de cair (amortecimento de quedas) em todas as direções (anterior, posterior, laterais e rolando sobre o ombro) e partindo de 4 níveis de dificuldade, dentro de uma evolução pedagógica (deitado, sentado, de cócoras e em pé).

Na parte principal do treinamento, foi realizado o treino da maneira correta de pegar no adversário e de deslocar-se; treino de sombra (sem o oponente); repetição estática e dinâmica das técnicas básicas (sem resistência do oponente); e treino de desequilíbrio. Também nesta parte do protocolo, realizou-se treino alternado efetuando a projeção do oponente ao solo, sem resistência do mesmo e o treinamento alternado de ataques tentando projetar o oponente, quando este só poderia defender-se, totalizando entre 30 e 35 minutos.

As técnicas enfatizadas neste protocolo foram somente as 3 das mais básicas indicadas por MENDEs $^{9}$ para o treinamento de crianças principiantes (O-soto-gari, O-uchi-gari, De-ashi-harai), por serem menos complexas e de fácil aprendizado.

Operíodo de volta à calma durou aproximadamente 12 minutos. Nele, os voluntários realizaram deslocamento, com uso da pegada no adversário, sem fazer qualquer resistência e alongamento global. Todos os treinos tiveram a supervisão e orientação de 2 professores e 5 monitores desta modalidade. Cada atividade teve tempo cronometrado para sua realização e para os intervalos de descanso entre elas.

\section{Método estatístico}

Para análise estatística, foi previamente fixado o nível alfa $=0.05$ para rejeição da hipótese nula. $\mathrm{O}$ processamento dos testes de hipótese foi realizado pelo software SPSS 17.0, sendo utilizado o teste de ShapiroWilk (para verificaçáo da normalidade) e os testes de Wilcoxon e t de Student para amostras pareadas para comparação entre os grupos.

\section{Resultados}

\section{Caracterização da amostra}

A amostra do estudo foi formada por 9 crianças com deficiência visual, com idade entre 6 e 12 anos. Das 9 crianças, 5 eram do sexo masculino, correspondendo a $55.6 \%$ e 4 eram do sexo feminino, correspondendo a $44.4 \%$. Destas, 7 apresentavam cegueira congênita e 2 deficiência visual. As características gerais da amostra estão expressas na TABELA 1. 
TABELA 1 - Características gerais da amostra.

\begin{tabular}{lccc}
\hline & Mínimo - Máximo & Média & Desvio Padráo \\
\hline Idade (em anos) & $6-12$ & 8,4 & $\pm 2,1$ \\
Peso (em quilogramas) & $19,6-41,3$ & 29,1 & $\pm 7,8$ \\
Altura (em metros) & $1,11-1,51$ & 1,27 & $\pm 0,13$ \\
IMC & $15,16-21,59$ & 18,01 & $\pm 1,95$ \\
\hline
\end{tabular}

A avaliação do equilíbrio das crianças com deficiência visual foi realizada por meio da Escala de Equilíbrio de Berg, do Teste de Alcance Funcional Anterior e da Estabilometria dos pés direito e esquerdo e do corpo (FIGURA 1).

A avaliaçáo por meio da Escala de Berg foi realizada pelo teste de Wilcoxon para amostras pareadas (FIGURA 1A). Registramos diferença estatisticamente significativa ( $\mathrm{p}$-valor $=0,0069^{*}$ ) entre as avaliaçóes realizadas antes $(42,2+8,7)$ e a realizada depois $(54,1+2,4)$ do protocolo de treinamento.

Para análise do Teste de Alcance Funcional Anterior utilizamos o teste $\mathrm{t}$ de Student para amostras pareadas (FIGURA 1B), no qual também registramos diferença estatisticamente significativa ( $\mathrm{p}$-valor $<0,0001^{*}$ ) entre as avaliaçôes realizadas antes $(11,6 \pm 6,5 \mathrm{~cm})$ e depois $(25,6 \pm 7,6 \mathrm{~cm})$ do treinamento.

Realizamos a avaliação do equilíbrio das crianças com deficiência visual por meio da Estabilometria. Para tanto, analisamos as oscilaçôes do pé esquerdo (FIGURA 1C), do pé direito e do corpo. Para comparação estatística entre os valores das oscilaçóes do pé esquerdo, utilizamos o teste $\mathrm{t}$ de Student para amostras pareadas e registramos diferença estatisticamente significante $\left(\mathrm{p}\right.$-valor $\left.=0,031^{*}\right)$ entre as avaliaçôes anteriores $(0,9 \pm 0,6 \mathrm{~cm})$ e posteriores $(0,4 \pm 0,2 \mathrm{~cm})$ ao treinamento. Para as oscilações do pé direito, realizamos o teste de Wilcoxon para amostras pareadas (FIGURA 1D). Também registramos diferença estatisticamente significante ( $\mathrm{p}$-valor $\left.=0,038^{*}\right)$ entre as avaliaçóes antes $(1,5+1,5 \mathrm{~cm})$ e depois $(0,8+0,6 \mathrm{~cm})$. Igualmente, o teste $\mathrm{t}$ de Student para amostras pareadas (FIGURA $1 \mathrm{E})$, identificou que as oscilaçóes do corpo demonstraram redução significativa ( $p$-valor= $\left.0,015^{*}\right)$ entre as avaliaçóes antes $(2.8 \pm 1.1 \mathrm{~cm})$ e depois $(1.6 \pm 0.7 \mathrm{~cm})$ do treinamento. 
FIGURA 1 - Análise da avaliação do equilíbrio das crianças com deficiência visual pela Escala de Equilíbrio de Berg, pelo Teste de Alcance Funcional Anterior e pela Estabilometria dos pés direito e esquerdo edo corpo.

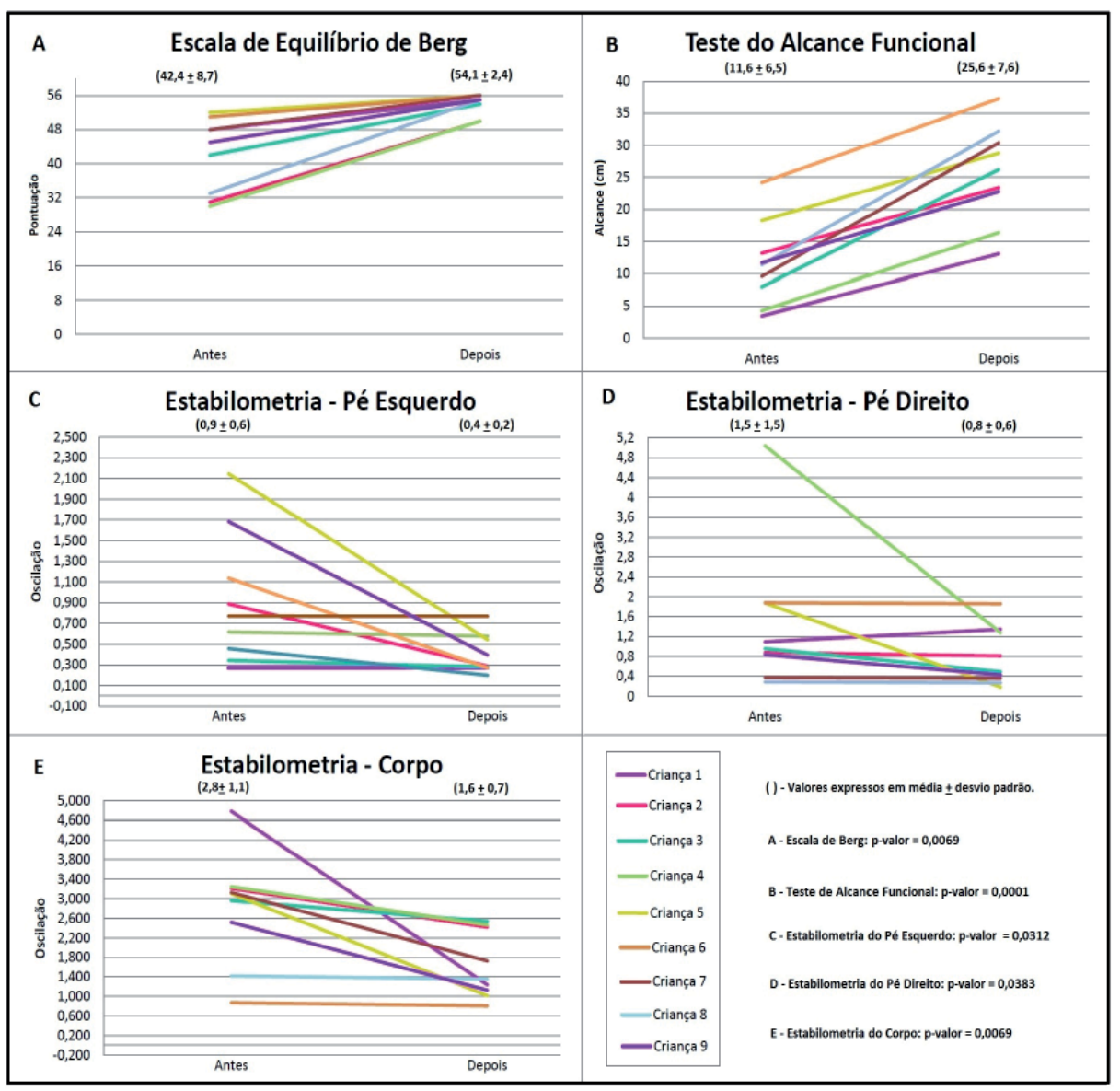

\section{Discussão}

Os resultados de nosso estudo indicam que a prática do judô é um método eficiente para o desenvolvimento do equilíbrio de crianças com deficiência visual. Este éo primeiro estudo a identificar um potencial terapêutico de um protocolo de treinamento através da motricidade do judô, objetivando a melhora do equilíbrio de crianças com deficiência visual.

Não encontramos na literatura estudos com intervençóes em crianças com deficiência visual que visassem melhorar o equilíbrio corporal e que tivessem amostra passível de comparaçóes adequadas com a do presente estudo.

Em nosso estudo, as crianças apresentaram melhora nos escores da Escala de Berg com o treinamento de judô. Lopes, Kitadai e OKAI ${ }^{10}$, realizaram um estudo com 12 crianças com deficiência visual, porém com idade entre 1 e 15 anos e as submeteram a um protocolo de tratamento fisioterapêutico, visando treinar marcha, equilíbrio, propriocepção e coordenação motora. $\mathrm{O}$ protocolo continha exercícios como: saltos, caminhada em superfície instável, caminhada nas pontas dos pés e calcanhares. Um dos testes específicos utilizados para avaliação do equilíbrio foi a Escala de Berg, no qual as crianças apresentaram inicialmente pontuação média de 36 pontos e, após o tratamento, obtiveram uma média de 44 pontos. Em nosso estudo, as médias foram de 42,2 e 54,1 pontos, antes e depois do treinamento, respectivamente. No entanto, em nosso estudo, além de a idade das crianças diferirem (6-12 anos), as crianças foram submetidas a 30 dias de treinamento, os quais foram realizados durante o período de 2 meses. Lopes, KitadaI e OKAI ${ }^{10}$ aplicaram seu protocolo por 20 meses, com uma sessão de fisioterapia por semana, totalizando 80 dias de treinamento.

Assim, o presente estudo apresentou resultados positivos em menor tempo. Isto se deve, talvez, aos 
constantes estímulos labirínticos, desequilíbrios, balanços, rotaçóes e estímulos de contato, comumente utilizados na prática do judô. Paralelamente, embora não tenhamos quantificado uma possível redução do medo de cair, acreditamos que isto possa ter influenciado os resultados deste estudo. Isto porque, o objetivo principal no combate de judô é desequilibrar o oponente, fazendo-o cair. Desta forma, durante o treino de judô, judocas estáo constantemente sujeitos aos movimentos imprevisíveis de seu adversário, que tenta desestabilizá-lo. Assim, além de possuir conhecimento de amortecimento de queda, é provável que, com o treinamento, o judoca adquira uma boa capacidade de equilíbrio ${ }^{11}$.

Sobre este assunto, Jankowicz-Szymanska, MikolajCZYK e WARDZALA ${ }^{12}$, demonstraram que judocas de 9 a 13 anos de idade têm melhor equilíbrio estático do que seus pares não-judocas. Ainda, Perrin et al. ${ }^{11}$, identificaram que judocas apresentam melhor controle postural do que bailarinas, com menor oscilação do centro de gravidade, independentemente da ausência da informação visual ou da perturbação da propriocepçáo. Concluíram, assim, que o Judô tem baixa dependência de aferências visuais. A sensibilidade transmitida pela forma de segurar o judogui (percepção tátil-cinestésica) é suficiente na luta do judô (percepção tátil-cinestésica) é suficiente na luta do judô, havendo maior facilidade em usar informaçóes proprioceptivas e somestésicas11. Em consonância, embora a IBSA (International Blind Sports Federation) divida os deficientes visuais em três classes que vão de atletas que têm alguma acuidade visual aos com cegueira total nas competiçóes esportivas, no judô todos disputam juntos, sendo separados apenas por categorias de peso ${ }^{8}$.
Matos et al. ${ }^{5}$, analisando as oscilaçóes corporais em testes estabilométricos em crianças com deficiência visual com idade entre 8 e 11 anos verificaram que estas possuem déficit no controle do equilibrio. Este resultado está em consonância com outros estudos que avaliaram o equilibrio de crianças com deficiência visual por meio de outros testes de avaliação do equilíbrio, justificando, portanto, a necessidade de intervenção nessa população, com o intuito de reduzir as repercussóes que a falta de estímulos visuais desencadeia no controle do equilíbrio.

Apesar de nosso estudo não apresentar um grupo controle e possuir um número relativamente pequeno de participantes, devido à grande dificuldade em selecionar um número significativo de participantes que se enquadrassem nos critérios de inclusão, a hipótese de que o judô pode ser utilizado como estratégia para melhorar o equilíbrio pôde ser confirmada. Além desses fatores, a grande diferença entre as idade dos voluntários deste estudo e, consequentemente, a discrepância quanto ao desenvolvimento motor das crianças, devem ser considerados para estudos futuros.

Os resultados do presente estudo poderáo colaborar para embasar recomendaçóes futuras e para o possível estabelecimento de protocolos de tratamento através da motricidade do judô especificamente a estes indivíduos.

A melhora do controle do equilibrio em crianças com deficiência visual, proporcionada através do protocolo utilizado neste estudo, deve favorecer a aquisição de habilidades motoras e influenciar positivamente na mobilidade destas crianças. Em consequência, a consequente reduçáo do risco de quedas e lesóes, pode contribuir para a independência funcional e auxiliar na promoção de autonomia social, melhorando a qualidade de vida. 


\begin{abstract}
Adapted Judo as a tool for balance rehabilitation of children with visual impairment

Children with visual impairment can present delay in the development of balance. Judo is an adapted sport to the visually impaired, but little is known about its effects on children with visual impairment. The aim of this study was to ensure if judo can improve the balance o visually impaired children. In this study, nine visually impaired children, aged between 6 and 12 years, who had never practiced judo, participated in a training protocol of this sport for 8 weeks. To assess balance, we applied the Berg Balance Scale (BBS), the Functional Reach Test (FRT) and Stabilometry, analyzing the oscillations of the left and right feet and of the body. To reject null hypothesis was previously set level alpha $=0,05$. We registered statistically significant difference for BBS ( $p$-value $=0,0069^{*}$ ) between assessments before $(42,2 \pm 8,7)$ and after $(54,1 \pm 2,4)$ training. We also found differences between the previous values $(11,6 \pm 6,5 \mathrm{~cm})$ and rear $(25,6 \pm 7,6 \mathrm{~cm})$ to training for the FRT ( $p$-value $<0,0001)$., for the oscillations of the left foot $(0,9 \pm 0,6 \mathrm{~cm}-0,4 \pm 0,2 \mathrm{~cm})(p$-value $=0,031)$, right foot $(1,5 \pm 1,5-0,8 \pm 0,6)$ ( $p$-value $=0,038)$ and body $(2,8 \pm 1,1 \mathrm{~cm}-1,6 \pm 0,7 \mathrm{~cm})$ ( $p$-value $=0,015)$. Judo can be an important tool in the strategy of balance rehabilitation of children with visual impairment.
\end{abstract}

KEYwoRds: Visually impaired persons; Postural balance; Martial arts; Sports.

\title{
Referências
}

1. Pascolini D, Mariotti, SP. Global estimates of visual impairment: 2010. Br J Ophthalmol. 2012;96(5):614-618.

2. Almeida TS, Araújo FV. Diferenças experienciais entre pessoas com cegueira congênita e adquirida: uma breve apreciação. Rev Interfaces Saúde Hum Tecnol. 2013;1(3).

3. França-Freitas MLP, Gil MSC. O desenvolvimento de crianças cegas e de crianças videntes. Rev Bras Educ Espec. 2012;18(3).

4. Maggi AB, Souza VR, Sinésio T, Machado DS, Vieira MM. A influência da visão no equilíbrio de crianças deficientes visuais congênitas e com visão normal. EFDeportes Rev Digital. 2011;154.

5. Matos MR, Matos CPG, Oliveira CS. Equilíbrio estático da criança com baixa visão por meio de parâmetros estabilométricos. Fisioter Mov. 2010;23(3):361-9.

6. Mesquita LS, Carvalho FT, Freire LS, Pinto Neto O, Zângaro RA. Effects of two exercise protocols on postural balance of elderly women: a randomized controlled trial. BMC Geriatrics. 2015;15(61).

7. Vieira AAU, Aprile MR, Paulino CA. Exercício físico, envelhecimento e quedas em idosos: revisão narrativa. Rev Equilíbrio Corp Saúde. 2014;6(1),23-31.

8. International Blind Sports Federation. Judô: General Information. Disponível em: http://www.ibsasport.org. Acesso em: 10 nov 2016.

9. Mendes MM. Lutas e Artes Marciais. Licenciatura em Educação Física a Distância. Belo Horizonte: Universidade FUMEC, 2009.

10. Lopes MCB, Kitadai SPS, Okai LA. Avaliação e tratamento fisioterapêutico das alteraçôes motoras presentes em crianças deficientes visuais. Rev Bras Oftalmol. 2004;63(3):155-161.

11. Perrin P, Deviterme D, Hegel F, Perrot C. Judô, better than dance, develops sensoriomotor adaptabilities involved in balance control. Gait Posture. 2002;15:187-194.

12. Jankowicz-Szymanska A, Mikolajczyk E, Wardzala R. Arch of the foot and postural balance in young judokas and peers. J Pediatric Orthopaedics B. 2015;24:456-460. 
Pinto ACPN, et al.

ENDEREÇO

Ana Carolina Pereira Nunes Pinto Rod. J uscelino Kubitschek, KM 2

Jardim Marco Zero

68.903-419 - Macapá - AP - Brasil E-mail: anacarolinapnp@hotmail.com
Submetido: $18 / 08 / 2016$

Revisado: $23 / 11 / 2016$

Aceito: 25/11/2018 